\title{
Impact of internet of things on business policy: the mediating role of marketing intelligence capability
}

\author{
Ansar Abbass* \\ Department of Business Administration, \\ Ghazi University, \\ DG, Khan, Pakistan \\ Email: ansarabbass630@gmail.com \\ *Corresponding author
}

\section{Khalid Mehmood}

Department of Marketing,

KU Leuven, Belgium

and

Center for Service Intelligence,

Ghent University, Belgium

Email: khalid.mehmood@ugent.be

and

Faculty of Management Sciences,

Ghazi University, Pakistan

\begin{abstract}
Innovative developments in internet of things (IoT) have invoked wonderful interest of researchers and as well as for practitioners. Studies suggest that IoT do not merely serves as an innovative tool for enterprise operations but also triggers impacts on business performance. As researchers increasingly raise interests about the business value of IoT, this study examines its direct and indirect managerial effect by investigating the link between IoT and business policy. Referring to the organisational capability perspective, the current research constructed the framework where the marketing intelligence competence mediates the impact of IoT capability on business policy formation. The data analysis was conducted to examine the hypotheses and an empirical survey was performed. The outcomes of study confirmed that mediating role of marketing intelligence capability in the link between IoT capability and business policy formation. Discussions with managerial implications are then elaborated.
\end{abstract}

Keywords: internet of things; IoT; marketing intelligence; business policy; organisational capability.

Reference to this paper should be made as follows: Abbass, A. and Mehmood, K. (xxxx) 'Impact of internet of things on business policy: the mediating role of marketing intelligence capability', Int. J. Business Information Systems, Vol. X, No. Y, pp.xxx-xxx.

Biographical notes: Ansar Abbass is an MPhil scholar of Department of Business Administration Ghazi University DG. Khan, Pakistan. His current research interests are in the area of marketing, IoT and AI in services, 
consumer behaviour, neuromarketing, decision sciences and marketing strategy. He is also working as Managing co-editor Business Management and Strategy Macrothink Institute, USA.

Khalid Mehmood is a doctoral candidate at the Department of Marketing (KU Leuven) and at the Center for Service Intelligence, Ghent University, Belgium. $\mathrm{He}$ is passionate about service research, with a specific focus on personalisation, IoT and $\mathrm{AI}$ in services, and customer experience. He is also working as Lecturer, Faculty of Management and Social Sciences, Ghazi University, DG Khan, Pakistan.

\section{Introduction}

Modern developments towards extensive globalisation, meticulousness of enterprise internationalisation and business integration, and the rapid development of innovative technologies have caused business environments to change rapidly and enormously. Today's customers are more informed and educated, more selective and demanding, and have a greater capacity of choice. This emergence of informed, connected, empowered and active customers have challenged the prevailing notion of value creation. Creating superior customer experience is considered essential in achieving satisfied and loyal customers and thus the eventual objective for organisations and their offerings (Mashingaidze and Backhouse, 2017). To respond effectively to changing internal situations and external environments, a firm must interact closely with changes through its distinctive capabilities to form a highly robust competitive strategy. This makes a firm's organisational capabilities especially critical facing competitions, since organisational capabilities occur as the cause of competitive advantage (Day, 1994). Internet of things (IoT) is a networking framework, where various kinds of physical devices containing sensors, software, connectivity and other embedded devices are interconnected to each other via networks enabling them to exchange information among them (Yoon et al., 2017). In contemporary global business environment, the evolution of IoT is considered as 'the next big thing' (Borgia, 2017) of information technology. The development of various IoT related technologies is expected to affect enterprises' managerial paradigm, including business policy. IoT has attracted attention as a possible source of strategic advantage for firms (Porter and Heppelmann, 2018). It may provide new business opportunities for companies, and may even change the future business operations and value creation (Iansiti and Lakhani, 2017). Therefore, aligning with the development of IoT has become critical for formulation and execution of a firm's business policy. The perceived capability of IoT suggests that planned decisions by the organisations are created more competently. By employing IoT, organisations will be capable of exploiting new business opportunities, identify possible threats, and keep up competitiveness (Hamidreza and Changiz, 2017). However, extent literature lacks explanation on the relationship between IoT and business policy. To fill this gap, this study intends to scrutinise the link between IoT and business policy. In addition, a firm is a value chain assembled with various value activities (Porter, 1985). These value activities include primary functional operations such as productions, marketing, sales and services, as well as supportive functional operations such as human resource management (HRM), information systems and research and development. In order to use IoT, a firm 
needs to integrate IoT with these functional operations. Therefore, these functional operations have influence on the link between IoT and business policy (Puspitasari and Jie, 2020). Among these functional operations, this research focuses on marketing for several reasons. First, marketing policy plays a key role in shaping overall business policy of a firm (Dobni and Luffman, 2003). Second, marketing is closely related to many other functional operations of a firm, such as production, sales and customer service (Guenzi and Troilo, 2006). Finally, IoT enabled customer solutions are expected to transform future marketing paradigm (Zancul et al., 2019). The term IoT is being used to describe the connectivity of things as "a system of uniquely identifiable and connected constituents (termed as internet-connected constituents) capable of virtual representation and virtual accessibility leading to an internet-like structure for remote locating, sensing, and/or operating the constituents with real-time data/information flows between them" (Ng and Wakenshaw, 2017).

Furthermore, marketing intelligence plays a pivotal role in the overall marketing strategy, because effective marketing decisions are based on a firm's ability of acquiring and interpreting accurate market knowledge (Trainor et al., 2013). That is why, the purpose of this study is to examine critical linkage between IoT and business policy, and the effect of marketing intelligence in this linkage. The following part discusses an evaluation of the relevant literature about the relationships between IoT, marketing intelligence and business policy (Mashingaidze and Backhouse, 2017). Then, it proposes a model which relates these three variables. Following that, the model is tested using a sample of Pakistani companies with global operations. Finally, the results are presented along with the theoretical and managerial implications of the study.

\section{Literature review}

IoT is not a new concept. The term itself was first coined by Kevin Ashton in 1999 (RFID Journal). In 2005, the International Telecommunication Union (ITU) envisioned the new dimension of connectivity for ICT: anytime and anyplace connectivity (on the move and with any gadget) for anyone to having connectivity for anything (human to thing, thing to thing). In the past years, when observing the reactions of different industries, it seems that the whole idea of IoT has not been quite realistic to them, which lead them to believe that it is a mere hype (Langley et al., 2020). However, ITU and some small businesses that have managed to introduce sensors to different equipment, view the emerging IoT as something evolving from the combination of visions and technology advancements as well as the next evolution of internet (Somnath, 2020). The whole idea of IoT is the high impact it has on users and their everyday-life as well as behaviour. This is also the reason why IoT products and services seek social or buyer acceptance. The effects of IoT will be visible for the private user in all aspects of their lives: at work, at home and socially (Atzori et al., 2010).

Nowadays, with the improvement of IT in organisations and the necessity to implement IT in accelerating project processes, it is essential to devise a fusion model of project management maturity and IT maturity (Hamidreza and Changiz, 2017). The value of IT to organisations has been a continuous topic of discussion since computers were introduced into organisations (Mashingaidze and Backhouse, 2017). IoT is defined 
differently by different research communities which lead readers to have real difficulty grasping the meaning of IoT. Additionally, it is not easy to get a big picture of IoT because different standardisation bodies, industries, researches and business alliances tend to add their own perspectives to the concept depending on their interests and approaches. One good way to look at IoT and later understand its ecosystem is to view it from this merged perspective of the different entities mentioned (Langley et al., 2020).

The extant literature has aimed for the IoT in a technical perspective. And this means that most of the literature has been written for the technical fields and also the enabling technologies of IoT (Mashingaidze and Backhouse, 2017).

In addition, authors also have written the industry applications of IoT in several domains (Kiel et al., 2017). At the same time, they also raised the technical issues (i.e., ...) of IoT which are needed to be solved. However, there are very limited researches from IoT in relation with business policy and marketing field. Especially, how the future business activities would change based on the development of IoT, such as consumer relation management, retailing, logistics, product development, online marketing, etc (Taylor et al., 2018). The IoT is a novel paradigm that is rapidly gaining ground in the scenario of modern wireless telecommunications (Langley et al., 2020). The US National Intelligence Council even listed the IoT as one of the six disruptive civil technologies with potential impact on US national power. From all the literature, it can be conducted that IoT has a huge impact in the future.

Figure 1 Conceptual model

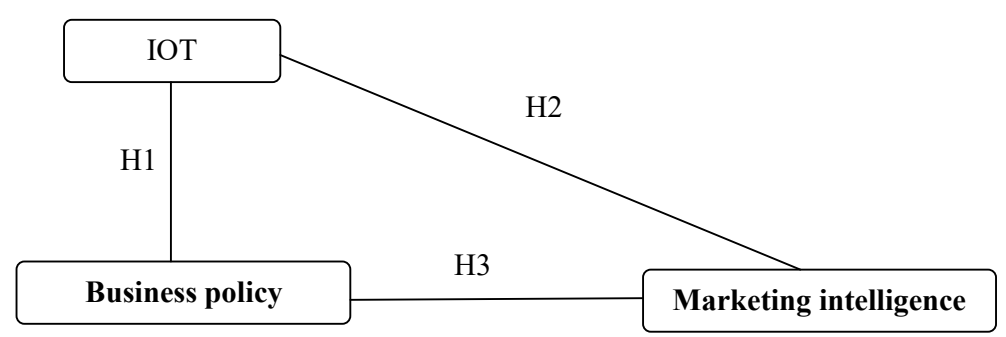

\section{Hypotheses}

\subsection{IoT and organisational capability}

Several researchers have elaborated the technological features of IoT (Borgia, 2017). These features are classified and summarised as follows:

- Ubiquitous sensing: This is the mechanism that the 'things' or devices in IoT perceive the surrounding physical environment, detect and record the environmental variations, and respond to the variations. Everywhere sensing is enabled by wireless sensor network (WSN) technologies (Borgia, 2017).

- Pervasive connectivity: IoT contains multiple layers of communication networking infrastructure to provide the pervasive communications among people and things and to form a smart environment (Gubbi et al., 2013). 
- Embedded computing: IoT devices contain embedded hardware and software to work intelligently within the environment. The embedded hardware includes processor chips, data storage units and power units. The embedded software includes embedded operating systems, mobile apps and middleware. In particular, IoT devices can be embedded further in other devices (Gubbi et al., 2013).

- Real-time analytics: IoT monitored and detected information are intangibly embedded in the environment around users, results in the generation of big data in real-time which are stored, distributed, processed, presented and interpreted in a faultless, efficient, and easily comprehensible method (Gubbi et al., 2013).

- Cloud support: Cloud services are deployed to assist the processing and storage of IoT analytics, and provide IoT users ubiquitous access of supporting services initiated by IoT devices around the smart environment (Bradley et al., 2015)

- Interactive user interface: Visualisation, touch and voice are serious for an IoT application as this allows the awareness and interaction of IoT users with the environment. 3D viewing and printing technologies, personal mobile assistants, wearable devices, and augmented-reality devices provide novel interface for users to interact with the smart environment (Weng and Lin, 2014).

- Interconnected smart products: IoT enables evolution of various products such as smart home appliances, robots, drones, unmanned cars, automated factory machines and business equipment, and many other innovative devices (Krotov, 2017).

- Cyber-physical convergence: The convergence of computer network, telecom network and IoT triggers further convergence of cyber space and physical space, and results in various smart spaces, such as smart home-based, smart office, smart factory, smart laboratory, smart store, smart marketplace, smart hospital, smart museum and smart city (Bradley et al., 2015).

With these technological advancement, IoT has been asserted as an important tool for organisational innovation and adoption in today's dynamic business environment (Lee and Lee, 2018), particularly for the organisations that have big quantities of data and connectivity. However, fewer studies, so far, have examined the capabilities required to implement IoT in an organisation, and in what way these narrate to different types of business policy, especially after the point of view of innovative and market-oriented companies. Therefore, to work with a required research construction of IoT and business policy, this study examines the importance of IoT competence more in business policy formation.

IoT capacity alludes to the organisations' capacity to coordinate firm capital and aptitudes emerging from IoT to line up with the organisations' vital bearings (Bharadwaj, 2000). IoT capability enables an organisation to exploit and incorporate the above mentioned IoT technological features for business value. By using IoT, firms are capable to identify latest professional openings and potential intimidation, and uphold competitiveness, thus establishing of an IoT capability for being the cause of competitive advantage (Yu et al., 2016). Depending on different industry sectors and business models, a firm with IoT capability can be competent in developing or deploying IoT core components for business applications, or it could be competent in making or using IoT 
connected products for business benefits, or it can be more efficient in implementing and operating IoT enabled value creations environments (Porter and Heppelmann, 2018).

\subsection{IoT and business policy}

From the strategic management perspective, cost leadership and differentiation are two important approaches to gain competitive advantage and basic choices a of business policy (Porter, 1985). Furthermore, researchers have argued about the price leadership and delineation both are not equally exclusive, but rather are compatible approaches in dealing by external situations, and an arrangement for strategies could lead to success in a variety of circumstances (Li and Lee, 2008).

Cost leadership policy requires organisational capabilities to achieve operational efficiency, including time efficiency, cost efficiency and flexibility. The functions of IoT enabled smart factory integrate technologies of many disciplines. IoT capability enables an enterprise to make extensive use of simulated intelligence, Information collection systems, simulation, automation, robotics, sensors, and networks about sophisticated precision machining and engineering. These systems make possible the organisation of efficient, mutual and sustainable industrial production to achieve cost leadership (Benias and Markopoulos, 2017).

Differentiation policy requires organisational capabilities to achieve product or service uniqueness for higher customer premium. Products or services differentiation are realised through innovation or customisation. Sensor-based data collected through IoT embedded products covers actions of customer purchase and use, and can therefore be analysed for getting much accurate and whole depiction of the customer's characteristics and of their preferences ( $\mathrm{Ng}$ et al., 2015). Smart laboratories can provide test fields for innovative products and services before delivery to customers. Thus, IoT capability could expand opportunities for product or service differentiation, moving competition away from cost alone.

Therefore, the following two hypotheses are proposed:

H1a IoT capability is positively related with cost leadership policy formation.

H1b IoT capability is positively related with differentiation policy formation.

\subsection{IoT and marketing intelligence}

Marketing intelligence is systematically collected and extracted information for making marketing decisions. Marketing intelligence is a critical component for overall marketing activities of a firm. Acquisition and effective use of market information is vital in shaping the firm's sustainable competitive advantage (Jaworski and Kohli, 1993). Marketing intelligence potential regarding an organisation's capability to gain knowledge regarding channel members, competitors, consumers and the wider market place atmosphere where it functions (Day, 1994). IoT capability is expected to enhance marketing intelligence capability, because IoT capability enables a firm with better ability to sense and collect information from customers and competitors (Yu et al., 2016). IoT capability indicates the ability in assimilation of the digital era with the physical world. This involves ability for convergence of the manufacturing techniques by the influence of complex analytics, computing, low-cost sensing, and original heights of connectivity delivered through an internet (Agarwal and Brem, 2015). IoT capability also facilitates the collaborations 
between firms and business partners. Information distribution and cooperation in IoT could happen among things, and people. Firms with IoT capability are easier to form virtual alliances or virtual groups with partners. These partners could be clients, suppliers, intermediaries, governments and competitors, all of which are important in IoT setting (Yu et al., 2016). Identifying the predefined occurrence is usually the first step for information sharing and collaboration. Information sharing and collaboration improve situational awareness and avoid information delay and deformation (Lee and Lee, 2018). This is the essence of marketing intelligence. In summary, the researcher suggests the following hypotheses:

H2 IoT capability is positively related with marketing intelligence capability.

\subsection{Marketing intelligence and business policy}

Marketing intelligence is about staying of the competitors by gathering information which can then be transformed to actionable intelligence and which can be applied to both short and long-term strategic planning (Narver, 2000). Marketing intelligence is considered as a strategic resource that enables a firm to strengthen its opportunity recognition, threat identification and achieve a positional advantage over its competitors (Day, 1994). MI is a set of integrated strategies, applications, technologies, architectures, processes and methodologies used to collect, store, retrieve and analyse data in order to support decision-making (Mashingaidze and Backhouse, 2017). Hence, it is related to the firm's business policy formation. Marketing intelligence capability enables a firm to acquire and analyse the cost structures and distinctive features of products and services of competitors and collaborators in the marketplace. It helps the firm to determine which market segments are suitable for cost leadership, and which market segments are feasible for differentiation. Market information about cost analytics at all levels needs to be collected and accurately analysed for a firm to maintain a viable cost leadership. Marketing intelligence about customer preferences and distinctive features are required for a firm to determine the need to differentiate its products against the need to keep its cost structure under control for offering distinctive product at a competitive value (Xie et al., 2016). Therefore, the following two hypotheses are proposed:

H3a Marketing intelligence capability is positively related with cost leadership policy formation.

H3b Marketing intelligence capability is positively related with differentiation policy formation.

\section{Methodology}

\subsection{Survey instrument}

The survey instrument was established using queries resulting after the works on data technology capabilities, marketing capabilities, and Porter's typology of competitive strategies discussed previously. We operationalised the research variables by means of multi-item seven-point Likert scale (Jarvis et al., 2003). Following the definition of information technology capability by Bharadwaj (2000), an organisation's IoT 
competence is measured here according to its capability to develop or deploy IoT-based resources, which include the tangible IoT resources, the intangible IoT resources, and the human IoT resources. The tangible IoT resources are physical things such as IoT components, IoT connected products, and IoT enabled smart environments. The intangible IoT resources are assets such as knowledge, know-how, and synergy about IoT. The human IoT resources comprise technical and managerial IoT staffs. Thus, the researcher's gauge the foundation capability rising by IoT with three elements according to utilisation of the three types of IoT-based resources. An organisation's advertising intelligence competency concerns its competency in intelligence generation, intelligence dissemination and responsiveness (Jaworski and Kohli, 1993). Advertising intelligence competency is operationalised by way of the availability and consumption of supplies and activities inside an organisation to collect and examine market place data, and consume it to create successful advertising plans. The ability to effectively gather and disseminate customer and competitor information is critical for marketing intelligence capability (Jaworski and Kohli, 1993). This four element scale was gotten (Trainor et al., 2013). The construct of cost leadership strategy formation stood through measurement of using four points that reflect the degree by which a firm forms a cost-oriented strategy. The formation of cost leadership strategy aims at achieving low manufacturing and distribution costs (Porter, 1985). The third item was the economic scale. A firm can usually lower cost through economies of scale or superior manufacturing processes. Finally, formation of cost leadership is often reflected in lower price of products or services (Dess and Davis, 1984). The construct of differentiation strategy formation stood through measurement of using four items that reflect the degree by that a firm forms a differentiation strategy. Differentiation implies being unique or distinct from competitors by providing superior functionality or customised feature within products or services to customers (Porter, 1985). Expending Porter's business plan outline, Miller (1988) discriminated differentiation strategy grounded on novelty from that grounded on intensive advertising. This distinction forms two items included in the construct. All items for this study measured with a seven-point Likert scale varying from 'strongly disagree' to 'strongly agree'. Furthermore, organisation size, IT branch and industry sector were used as control variables, because all these variables had been renowned in numerous analyses to assume deployment of information technologies. Table 1 illustrates the items utilised to compute individual variables of both independent and dependent constructed variables.

\subsection{Sample and data collection}

Enterprises operating in Pakistan were surveyed for testing the hypotheses. A questionnaire designed in accordance from Table 1 was used as the survey tool for data collection. It was then pretested with 13 executives and managers. The pretesting focused on tool clearness, question phrasing and validity. Respondents from the representative sample were invited to evaluate and analyse the statements and wording of the survey tool during the pre-test. Their comments and suggestions were inculcated to make the questionnaire more comprehensive and easy to understand for respondents and to establish content validity. A sample of 100 organisations was randomly chosen from the top 500 list of the largest companies in Pakistan published by a Pakistan marketing 
research organisation. Most of the companies in the list are public listed corporations with international operations. The study took three months to complete and was primarily done via e-mail and postal mail and then surveyed through telephone calls and in-person visits. The total of 217 responses was gathered, out of which 15 were impracticable for analysing and were eliminated. The remaining 202 responses were used for final analysis, with a response rate of $20.2 \%$. The mean differences between participating and non-participating organisations were matched along organisational attributes by means of $\mathrm{t}$-tests and all statistics were non-significant $(\mathrm{p}>0.5)$. Furthermore, the responses were categorised into two sets in order to examine whether there was any response bias? The reactions got during the initial two months were delegated early returns, and those got during the most recent months as late returns. The two groups were then looked at for any critical distinction in reactions utilising the chi-square test of independence.

Table 1 Constructs and items used in the survey

\begin{tabular}{ll}
\hline & Construct and item description (1-strongly disagree, 7 -strongly agree) \\
\hline IoT: internet of things capability \\
\hline IoT1 $\quad \begin{array}{l}\text { My company is competent in developing or deploying IoT technologies such as IoT } \\
\text { components, IoT connected products or IoT enabled environments }\end{array}$ \\
IoT2 $\quad$ We possess sophisticated IoT knowledge, intelligence and synergy \\
IoT3 $\quad$ Our employees are proficient in IoT technologies and related managerial topics \\
\hline MIC: marketing intelligence capability \\
\hline MIC1 $\quad$ My company is competent in collecting information about customers and competitors \\
MIC2 $\quad$ We are proficient in tracking customer needs and wants \\
MIC3 $\quad$ We are skilful in analysing and disseminating marketing information \\
MIC4 $\quad$ We are competent in developing effective marketing programs \\
\hline CLP: cost leadership policy formation \\
\hline CLP1 $\quad$ We provide low cost products or services based on manufacturing efficiency \\
CLP2 $\quad$ Our products or services have lower distribution cost than our competitors \\
CLP3 $\quad$ We develop and deliver products or services with economy of scale \\
CLP4 $\quad$ Our products or services have lower prices than competitors in the market \\
\hline DPS: differentiation policy formation \\
\hline DFP1 $\quad$ We deliver products or services with superior functionality to our competitors \\
DFP2 $\quad$ We provide products or services with customised feature to our customers \\
DFP3 $\quad$ Our firm differentiates our products or services based on innovation \\
DFP4 $\quad$ Our firm differentiates our products or services based on intensive marketing \\
\hline Control variables (rescaled) \\
\hline Industry: industry sectors of firms \\
1 on behalf of service organisations and 0 on behalf of manufacturing organisations \\
Firm size: total number of employees \\
IT size: total numbers of IT staff \\
\hline
\end{tabular}

No significant difference was found among the two groups, supporting that response bias is not any problem in this research (Armstrong and Overton, 1977). Table 2 demonstrates the profile of final sample list. 
Table 2 Profile of the final sampling firms

\begin{tabular}{lcc}
\hline & Sample size & Percentage \\
\hline Industry & & \\
$\quad$ Manufacturing & 92 & $45.5 \%$ \\
$\quad$ Services & 110 & $54.5 \%$ \\
$\quad$ Total & 202 & $100.0 \%$ \\
Firm size & & \\
$\quad$ Under 100 & 50 & $24.8 \%$ \\
100-199 & 53 & $26.2 \%$ \\
200-499 & 40 & $19.8 \%$ \\
500 and above & 59 & $29.2 \%$ \\
Total & 202 & $100.0 \%$ \\
IT department size & & \\
Under 5 & 67 & $33.2 \%$ \\
5-19 & 62 & $30.7 \%$ \\
20 and above & 73 & $36.1 \%$ \\
Total & 202 & $100.0 \%$ \\
\hline
\end{tabular}

\section{Results}

Our goal was to examine the influence of an organisation's IoT capability on advertising intelligence capability and business policy formation, and the possible mediation role of marketing intelligence capability. The empirical results were expected to demonstrate that a firm's formation of business policy, such as cost leadership policy and differentiation policy, is influenced by IoT capability and marketing intelligence capability. The results were also expected to verify the mediating role of marketing intelligence capability in the link amongst IoT capability and business policy formation. Finally, the results were used to test the relationship between IoT capability and marketing intelligence capability.

\subsection{Reliability and validity}

The reliability of the survey tool was tested using Cronbach's (1951) alpha to assess the internal reliability of the proposed constructs listed in Table 1. Cronbach's alpha tests the inter-relationship between the items comprising of concept to examine if the items measure a single concept. Nunnally and Bernstein (1994) recommended a threshold alpha value of 0.7 further suggested the reliability rules for determining significance: $\alpha<0.70$ (unacceptable), $0.70 \leq \alpha<0.80$ (fair), $0.80 \leq \alpha<0.90$ (good), and $\alpha>0.90$ (excellent). Content validity states to the degree for what the tool measures what it is designed to measure? Many of this research measures were adopted from applicable studies. Although basing the study on the established works provided a substantial level of validity, the study's validity was additionally enhanced through pre-testing the tool on the panel of professionals including 13 business executives and managers. Table 3 summarises the descriptive statistics and results of the validity and reliability tests. 
Table 3 Descriptive statistics, reliability and validity test

\begin{tabular}{ccccccc}
\hline & & & & Cronbach's alpha & $\begin{array}{c}\text { Cronbach's alpha } \\
\text { if item deleted }\end{array}$ & $\begin{array}{c}\text { Factor loading on } \\
\text { single factor }\end{array}$ \\
\hline IoT & IoT1 & 4.123 & 1.554 & 0.815 & 0.752 & 0.851 \\
& IoT2 & 3.671 & 1.479 & & 0.731 & 0.864 \\
& IoT3 & 4.708 & 1.554 & & 0.756 & 0.849 \\
MIC & MIC1 & 4.755 & 1.022 & 0.920 & 0.922 & 0.854 \\
& MIC2 & 4.787 & .931 & & 0.886 & 0.923 \\
& MIC3 & 4.828 & .931 & & 0.901 & 0.890 \\
& MIC4 & 4.764 & .857 & & 0.878 & 0.940 \\
CLP & CLP1 & 4.329 & .910 & 0.951 & 0.933 & 0.931 \\
& CLP2 & 4.375 & .863 & & 0.937 & 0.941 \\
& CLP3 & 3.988 & .729 & & 0.943 & 0.937 \\
& CLP4 & 4.724 & .990 & & 0.930 & 0.946 \\
DFP & DFP1 & 4.675 & .962 & 0.891 & 0.837 & 0.911 \\
& DFP2 & 4.616 & 1.106 & & 0.859 & 0.872 \\
& DFP3 & 4.616 & 1.039 & & 0.870 & 0.848 \\
& DFP4 & 4.787 & .959 & & 0.873 & 0.848 \\
\hline
\end{tabular}

Table 4 Factor analysis

\begin{tabular}{llcccc}
\hline Construct & Item & Factor1 & Factor2 & Factor3 & Factor4 \\
\hline IoT & IoT1 & .842 & .112 & .133 & .047 \\
& IoT2 & .817 & .086 & .130 & .246 \\
MIC & IoT3 & .838 & .042 & .084 & .106 \\
& MIC1 & .121 & .781 & .225 & .231 \\
& MIC2 & .053 & .902 & .157 & .180 \\
& MIC3 & .051 & .812 & .250 & .245 \\
CLP & MIC4 & .122 & .853 & .239 & .294 \\
& CLP1 & .099 & .166 & .908 & .189 \\
& CLP2 & .168 & .306 & .820 & .281 \\
\multirow{5}{*}{ DFP } & CLP3 & .184 & .293 & .819 & .268 \\
& CLP4 & .092 & .186 & .911 & .214 \\
& DFP1 & .139 & .252 & .257 & .819 \\
& DFP2 & .163 & .228 & .153 & .831 \\
& DFP3 & .169 & .249 & .196 & .775 \\
\hline
\end{tabular}

The reliability of the mechanism was examined using composite reliability estimates by employing Cronbach's $\alpha$. Altogether, the coefficients surpassed Nunnally's recommended level (0.70) of internal reliability (Nunnally and Bernstein, 1994). In addition, factor analysis was executed to confirm the validity. The results supported the constructs of the research model. The discriminant validity was confirmed since items for every constructs laden to only aspects by all loadings greater than 0.8 . These results confirmed that each of the concepts in our hypothesised model is unidimensional and 
factorial distinct, and that all items used to operationalise a construct is loaded onto an only factor.

Table 4 presents the results of a factor analysis. A four factor arrangement appeared with all predefined signs loading on to their own constructs, thereby avowed convergent validity and unidimensionality of the constructs. The model explained $80.665 \%$ of the variance.

Table 5 summarises the correlations among different factors. We also assessed discriminant validity on the basis of the construct correlation that (Campbell and Fiske, 1959) proposed. The tests indicated acceptable results with respect to discriminant validity.

Table 5 Construct correlation

\begin{tabular}{llccccccc}
\hline Construct & 1 & 2 & 3 & 4 & 5 & 6 & 7 \\
\hline 1 & IoT & 1 & & & & & & \\
2 & MIC & $0.254^{* *}$ & 1 & & & & & \\
3 & CLP & $0.322^{* *}$ & $0.532^{* *}$ & 1 & & & & \\
4 & DFP & $0.355^{* *}$ & $0.580^{* *}$ & $0.576^{* *}$ & 1 & & & \\
5 & Industry & 0.131 & -0.062 & 0.080 & 0.046 & 1 & & \\
6 & Firm size & 0.150 & 0.006 & 0.099 & 0.055 & -0.100 & 1 & \\
7 & IT size & 0.148 & 0.068 & 0.148 & 0.138 & $-2.790^{* *}$ & $0.402^{* *}$ & 1 \\
\hline
\end{tabular}

\subsection{Tests of hypotheses}

To test the research hypotheses, several regression analysis were done of using SPSS version 21. The researchers observed the degree where the data encountered suitable statistical assumptions in the case of several regression analyses such as normality and linearity, and our data met the essential assumptions. Table 6 summarises the test results regarding the parameter estimates and $\mathrm{p}$-values of the hypotheses.

In Table 6, the results supported our hypotheses. The direct effects of IoT on CLP and DFP, IoT on MIC, and MIC on CLP and DFP are tested significant. In the links of IoT on CLP of Hypothesis H1a and IoT on DFP of Hypothesis H1b, in addition to the found direct effects, partial mediation effects of MIC in the links were also found. This indicates that IoT capability influences business strategy formation with a direct effect and through a mediation effect. The test procedure concerning mediation follows the suggestion of Baron and Kenny (1986). We compared the proposed mediation model with an alternative direct effect model without MIC variable. The mediation model explains more variance on CLP $\left(\mathrm{R}^{2}=0.343\right)$ and DFP $\left(\mathrm{R}^{2}=0.393\right)$ than the $\left(\mathrm{R}^{2}=0.119\right.$ and $\left.\mathrm{R}^{2}=0.135\right)$ have direct effect model. The test results show that positive relationships exist between IoT and MIC $(\beta=0.271, p<0.001)$, between MIC and CLP $(\beta=0.533$, $p<0.001)$, and among MIC and DFP $(\beta=0.579, p<0.001)$. Furthermore, the significant relationships between IoT and CLP $(\beta=0.291, \mathrm{p}<0.001)$ and between IoT and DFP $(\beta=0.340, p<0.001)$ in the direct effect model is greater than those in the mediation model $(\beta=0.158, \mathrm{p}<0.05$ and $\beta=0.197, \mathrm{p}<0.01)$. Taking into account, these results as a whole, we thus conclude that influence of IoT competence on business strategy formation is partially mediated thru marketing intelligence capability. The effects of paths are summarised in Table 7. 
Impact of internet of things on business policy

Table 6 Tests results of the hypothesised model




Table 7 Effects of paths in the hypothesised model

\begin{tabular}{lcc}
\hline Hypothesis & Path & Effect from test results \\
\hline H1a & IoT $\rightarrow$ CLP & Direct effect supported \\
& & Partial mediation of MIC supported \\
H1b & IoT $\rightarrow$ DFP & Direct effect supported \\
& & Partial mediation of MIC supported \\
H2 & IoT $\rightarrow$ MIC & Direct effect supported \\
$\mathrm{H} 3 \mathrm{a}$ & MIC $\rightarrow$ CLP & Direct effect supported \\
H3b & MIC $\rightarrow$ DFP & Direct effect supported \\
\hline
\end{tabular}

\section{Discussion}

This research examined the impact of a firm's IoT capability upon business policy formation, and tested the possible mediating role of marketing intelligence capability. The results of the study made critical theoretical and managerial contribution. The study, by investigating IoT effects on business policy, extends the extant scarce literature on IoT and its contribution to business. This study fills the gap in existing IoT literature and will open up the avenues for future research. From a managerial perspective, the results of the study show that IoT has the potential to aid managers in development of their cost leadership as well as differentiation strategies. By supporting the study's hypotheses, this research helps managers and experts realise links between organisational capabilities and business policy formation. First, the cultivation of organisational capabilities, overall, it likely to improve firm's business strategies and further elevates its competitive advantage (Day, 1994). This research verifies the positive connection among the organisational capabilities and business strategy formation. In particular, our results support the positive correlations between two different organisational capabilities and the formation of two types of business polices. The findings demonstrate that together IoT capability and marketing intelligence capability have positive effects for the formation of both cost leadership policy and differentiation policy, which could further lead to competitive advantage (Porter, 1985). Therefore, the study serves to guide business managers that firms should do more than just invest in innovative technologies or marketing operations. They need to identify and build distinctive capabilities and put them in productive use. This study suggests that both IoT capability and marketing intelligence capability are worthy of attention in this regards. The findings that these capabilities may impact business policy formation indicate that their influence on a firm are cross-functional and may transcend managerial hierarchy.

Second, this study identifies a mediator in the association between IoT and business policy. While IoT capability is shown to positively influence business policy formation, our findings also point out that the relationship between IoT capability and business policy formation is partially mediated by marketing intelligence capability. Our study is distinctive that it explores the relationship between IoT capability and marketing intelligence capability, and reveals the mediating role of marketing intelligence capability on the relationship among IoT capability and business policy formation. For the partial mediation to be established, both of the links between IoT capability and marketing intelligence capability and among marketing intelligence capability and business policy 
formation need to be significant, and the influence of IoT capability on business policy formation is alleviated with the presence of marketing intelligence capability (Baron and Kenny, 1986). That is, an adding to the direct consequence of IoT capability on business policy formation, there is also an indirect effect through marketing intelligence capability. These two effects contribute to the total effect of IoT capability on business policy formation. From the literature contribution perspective, few of the extant studies refer to what happens to the indoor of a firm when IoT is introduced. Furthermore, most of the present research draws more notice to the analysis of how IoT could pressure business performance than to the debate of how IoT and marketing function together on business policy through the mediating role of marketing intelligence. Our findings support not only the marketing orientation concept of Jaworski and Kohli (1993), but also the hierarchy model of capabilities of grant. From the managerial implication perspective, the marketing department in a firm has to be skilful enough at sensing and understanding the external environment. If a business policy of a firm fits with its business environment, its outcomes are increasingly enhanced. Thus, a marketing department in a firm turns to be critical in the firm to facilitate that firm's business policies fit along with its environment. Our findings suggest that IoT capability can facilitate the marketing department of a firm for the generation, dissemination and analysis of marketing intelligence, so as to help shaping the firm's business policy for competitive advantage.

\section{Conclusions and recommendation}

Finally, our results indicate the similar effects of organisational capabilities on the two types of business policies. Both cost leadership policy formation and differentiation policy formation are positively influenced by IoT capability and marketing intelligence capability. This demonstrates that IoT capability and marketing intelligence capability are both enabling capabilities for business policy formation, regardless of the strategy typology. In essence, IoT capability and its output, pervasive sensing and connectivity with embedded analytics, enable firms to deploy and operate in smart environments, and thus could enhance the functional level operations with efficiency and flexibility to achieve price leadership or either differentiation, or a mixture of both. In addition, it is also because of the cross-functional nature of pervasive sensing and connectivity with embedded analytics, IoT capability can have a positive influence on some other organisational capabilities, such as marketing intelligence capability. Marketing intelligence capability and its output, marketing intelligence, enable firms to anticipate and better comprehend the customer needs and the competitive situation, to process this data faster and to develop products and services with lower cost or with differentiated features, which empower firms to sustain a competitive advantage. Furthermore, IoT capability and marketing intelligence capability may facilitate firms to discover opportunities for improvement and novel solutions. One of the opportunities is to explore the feasibility of mass customisation, which may achieve cost leadership and differentiation simultaneously. 


\section{Future research direction}

There can be many prospects for further study in the list of recommendations. But they can be combined in further research so that the common themes can be used as guiding principle, e.g., further studies into data management will also shed more light for instance on identifying the application areas where most after sales needs are. Further studies can be conducted to explore how the currently successful business model fit under the IoT applications with the company's offering and take that opportunity to study a combination of those business models to generate possible new ones. Furthermore, there have been many value creation methods and motivation identified in this study, one important follow-up study could be to understand means to capture those values in order to identify different revenue streams. The study would open up the possibility to identify latent ideas and their monetisation.

\section{References}

Agarwal, N. and Brem, A. (2015) 'Strategic business transformation through technology convergence: implications from General Electric's industrial internet initiative', International Journal of Technology Management, Vol. 67, Nos. 2-4, pp.196-214.

Armstrong, J.S. and Overton, T.S. (1977) 'Estimating nonresponse bias in mail surveys', Journal of Marketing Research, Vol. 14, No. 3, p.396.

Atzori, L. et al. (2010) 'The internet of things: a survey', Computer Networks, Vol. 54, No. 15, pp.2787-2805.

Baron, R.M. and Kenny, D.A. (1986) 'The moderator-mediator variable distinction in social psychological research: conceptual, strategic, and statistical considerations', Journal of Personality and Social Psychology, Vol. 51, No. 6, pp.1173-1182.

Benias, N. and Markopoulos, A.P. (2017) 'A review on the readiness level and cyber-security challenges in industry', in Design Automation, Computer Engineering, Computer Networks and Social Media Conference (SEEDA-CECNSM), South Eastern European.

Bharadwaj, A.S. (2000) 'A resource-based perspective on information technology capability and firm performance: an empirical investigation', MIS Quarterly, Vol. 24, No. 1, pp.169-196.

Borgia, E. (2017) 'The internet of things vision: key features, applications and open issues', Computer Communications, Vol. 54, No. 27, pp.1-31.

Bradley, D., Russell, D., Ferguson, I., MacLeod, A. and White, R. (2015) 'The internet of things the future or the end of mechatronics', Mechatronics, Vol. 15, No. 2, pp.57-74.

Campbell, D.T. and Fiske, D.W. (1959) 'Convergent and discriminant validation by the multitrait-multimethod matrix’, Psychological Bulletin, Vol. 56, pp.81-105.

Cronbach, L. (1951) 'Coefficient alpha and the internal structure of tests', Psychometrika, Vol. 14, No. 3, pp.297-334.

Day, G.S. (1994) 'The capabilities of market-driven organizations', Journal of Marketing, Vol. 58, No. 4, pp.37-52.

Dess, G.G. and Davis, P.S. (1984) 'Porter's (1980) generic strategies as determinants of strategic group membership and organizational performance', Academy of Management Journal, Vol. 27, No. 3, pp.467-488.

Dobni, C.B. and Luffman, G. (2003) 'Determining the scope and impact of market orientation profiles on strategy implementation and performance', Strategic Management Journal, Vol. 24, No. 6, pp.577-585.

Gubbi, J. et al. (2013) 'Internet of things (IoT): a vision, architectural elements, and future directions', Future Generation Computer System, Vol. 29, No. 7, pp.1645-1660. 
Guenzi, P. and Troilo, G. (2006) 'Developing marketing capabilities for customer value creation through marketing-sales integration', Industrial Marketing Management, Vol. 35, No. 8, pp.974-988.

Haller, S., Karnouskos, S. and Schroth, C. (2009) 'The internet of things in an enterprise context', Future Internet - FIS 2008, pp.14-28, doi:10.1007/978-3-642-00985.

Hamidreza, E. and Changiz, V. (2017) 'Application of IT in project management using structural equation modelling', Int. J. Business Information Systems, Vol. 24, No. 4, pp.529-545.

Iansiti, M. and Lakhani, K.R. (2017) 'Digital ubiquity - how connections, sensors, and data are revolutionizing business', Harvard Business Review, Vol. 92, No. 11, pp.91-99.

Jarvis, C.B., MacKenzie, S.B. and Podsakoff, P.M. (2003) 'A critical review of construct indicators and measurement model misspecification in marketing and consumer research', Journal of Consumer Research, Vol. 30, No. 2, pp.199-218.

Jaworski, B.J. and Kohli, A.K. (1993) 'Market orientation: antecedents and consequences', Journal of Marketing, Vol. 57, No. 3, pp.53-70.

Kiel, D. et al. (2017) 'The influence of the industrial internet of things on business models of established manufacturing companies - a business level perspective', Technovation, December, Vol. 68, pp.4-19.

Krotov, V. (2017) 'The internet of things and new business opportunities', Business Horizons, Vol. 60, No. 6, pp.831-841.

Langley, D.J. et al. (2020) 'The internet of everything: smart things and their impact on business models', Journal of Business Research, December, Vol. 105, pp.1-454.

Lee, I. and Lee, K. (2018) 'The internet of things (IoT): applications, investments, and challenges for enterprises', Business Horizons, Vol. 58, No. 4, pp.431-440.

Li, C.B. and Lee, J.J. (2008) 'Achieving superior financial performance in China differentiation, cost leadership, or both?', Journal of International Marketing, Vol. 16, No. 3, pp.1-22.

Mashingaidze, K. and Backhouse, J. (2017) 'The relationships between definitions of big data, business intelligence and business analytics: a literature review', Int. J. Business Information Systems, Vol. 26, No. 4, pp.488-505.

Miller, D. (1988) 'Relating Porter's business strategies to environment and structure: analysis and performance implications', Academy of Management Journal, Vol. 31, No. 2, pp.280-308.

Narver, S. (2000) 'Intelligence generation and superior customer value', Journal of the Academy of Marketing Science, Vol. 28, No. 1, p.120.

Ng, I., Scharf, K., Pogrebna, G. and Maull, R. (2015) 'Contextual variety, internet-of-things and the choice of tailoring over platform: mass customisation strategy in supply chain management', International Journal of Production Economics, Vol. 159, No. 5, pp.76-87.

Ng, I.C.L. and Wakenshaw, S.Y.L. (2017) 'The internet-of-things: review and research directions', International Journal of Research in Marketing, Vol. 34, No. 1, pp.3-21.

Nunnally, J. and Bernstein, I. (1994) Psychometric Theory, McGraw-Hill, New York.

Porter, M.E. (1985) Competitive Advantage, Free Press, New York.

Porter, M.E. and Heppelmann, J.E. (2018) 'How smart, connected products are transforming competition', Harvard Business Review, Vol. 92, No. 1, pp.64-88.

Puspitasari, I. and Jie, F. (2020) 'Making the information technology-business alignment works: a framework of IT-based competitive strategy', Int. Journal of Business Information System, Vol. 34, No. 1, pp.59-82.

Somnath, D. (2020) 'Green IS - information system framework to support environmental sustainability of firms', Intr. Journal of Business Information Systems, Vol. 34, No. 2, pp.83-103.

Taylor, M., Reilly, D. and Wren, C. (2018) 'Internet of things support for marketing activities', Journal of Strategic Marketing, Vol. 28, No. 2, pp.149-160. 
Trainor, K.J. et al. (2013) 'Effects of relational proclivity and marketing intelligence on new product development', Marketing Intelligence \& Planning, Vol. 31, No. 7, pp.788-806.

Weng, W.H. and Lin, W.T. (2014) 'A scenario analysis of wearable interface technology foresight', in International Conference on Electronic Business (ICEB), Taipei.

Xie, K., Wua, Y., Xiao, J. and Hu, Q. (2016) 'Value co-creation between firms and customers: the role of big data-based cooperative assets', Information \& Management, Vol. 53, No. 8, pp.1034-1048.

Yoon, T.E. et al. (2017) 'User acceptance of business intelligence application: motivation to learn, technology, social influence, and situational constraints', Int. J. Business Information Systems, Vol. 26, No. 4, pp.432-450.

$\mathrm{Yu}, \mathrm{X}$., Nguyen, B. and Chen, Y. (2016) 'Internet of things capability and alliance', Internet Research, Vol. 26, No. 2, pp.402-434.

Zancul, E.d.S. et al. (2019) 'Business process support for IoT based product-service system', Business Process Management Journal, Vol. 22, pp.305-323. 